\title{
Simulation Analysis of Switch Controlled Power Filters for Harmonic Reduction
}

\author{
V. Narasimhulu' ${ }^{1}$, D. V. Ashok Kumar ${ }^{2}$ and Ch. Sai Babu ${ }^{3}$ \\ ${ }^{1}$ Research Scholar, JNTUK, KAKINADA, Andhra Pradesh, India \\ ${ }^{2}$ Professor of E.E.E \& Dean Administration, RGMCET, Nandyal, Andhra Pradesh, India \\ ${ }^{3}$ Professor of E.E.E and Officer on Special Duty, JNT University, Kakinada, Andhra Pradesh, India
}

\begin{abstract}
This paper presents an implementation of a three phase Voltage Source Converter (VSC) as shunt active power filter for harmonic reduction under nonlinear loads. Traditionally, the Synchronous Condenser, Thyristor Controlled Reactor (TCR) and Thyristor Switched Capacitor (TSC) are implemented for harmonic reduction under nonlinear loads. The passive filters are required to achieve the desired harmonic reduction in traditional methods. The addition of filters suffers from the resonance. The proposed methodology avoids the requirement of additional filters to achieve the better total harmonic reduction for various types of loads. Sinusoidal Pulse Width Modulation (SPWM) is used to control Voltage Source Converter. The results are compared with traditional methods. The proposed work is validated through simulation results.
\end{abstract}

Key words: Voltage Source Converter, TCR, TSC, and Total Harmonic Distortion.

\section{INTRODUCTION}

Power quality has assumed increasing significance in view of the extensive make use of of power electronic tools. For reactive power compensation, in addition to shunt capacitors and reactors, static var compensators (SVCs) are used. They are also employed to solve numerous power quality issues such as mitigating voltage sags, voltage regulation, negative sequence voltages, over voltages after fault clearing etc. In several cases, mis-operation of the protective equipment is take place due to harmonics and contributing to a decrease in power quality. Harmonic filters are employed to absorb adverse harmonics. When a nonlinear load is supplied from a supply voltage of $60-\mathrm{Hz}$ or $50-\mathrm{Hz}$ frequency, it draws currents at more than one frequency, resulting in a distorted current waveform. Fourier analysis of this distorted current waveform resolves it into its fundamental component and different harmonics. Harmonic distortion is a growing concern for many customers and the utilities because of increasing application of power electronics equipment. Different categories of harmonic produced loads are supplied by the electric utilities such as Domestic loads, Ripple control systems for regulating hot-water loads, Medium-sized industrial loads, and Large loads [1].

Traditionally, passive filters have been employed to mitigate current harmonics of the supply system. However, these strategies suffer from resonance [2]. The resonance problem of passive filters is mitigated using Active power filters [3][5]. They are more effective in harmonic compensation and have good performance [6]-[8]. So in this paper, Voltage Source Converter as Shunt Active power Filter using SPWM is proposed for harmonic reduction under non-linear loads.

\section{TRADITIONAL METHODS \\ Synchronous Condensers}

Synchronous condensers have played a key role in control of voltage and reactive power for more than fifty years. Practically, the synchronous condenser is a synchronous machine associated to the power system. Behind a synchronous condenser is coordinated, the current of field is adjusted to either inject or absorb reactive power according to the power system requirement. The unit can provide constant reactive power control when employed with the appropriate automatic exciter. This Synchronous Condensers have been employed at both transmission and distribution voltage levels to maintain voltages and to improve stability within preferred limits under changeable load circumstances and eventuality situations. However, synchronous condensers are infrequently used today since they require considerable foundations and a considerable quantity of starting and protective apparatus. The Synchronous Condensers are also contributed to the short circuit current and they can't be controlled quickly to compensate for rapid change of loads. Moreover, their losses and the cost are higher when compared with static compensators. The advantage of this unit lies in their elevated temporary overload competence [1].

\section{Thyristorized VAR Compensators}

As similar to the synchronous condenser, the aim of accomplishing fine control over the complete VAR range, has been satisfied with the improvement of static compensators (SVC) but with the benefit of quicker response times [9], [10]. Static VAR compensators (SVC) include standard reactive power elements such as capacitors and reactors which are controlled to supply hasty and erratic reactive power. They are two basic categories, such as thyristor-switched capacitor (TSC) and thyristor-controlled reactor (TCR).

\section{Thyristor-Switched Capacitors}

The basic configuration of a thyristor-switched capacitor (TSC) which is the group of a static compensator is shown in 
Figure 1. First it is introduced by ASEA in the year of 1971 [11], the shunt capacitor bank is divide into properly small steps, which are independently switched in and out by means of bidirectional thyristor controlled switches. Each 1- $\varnothing$ branch includes two main parts, the capacitor branch $\mathrm{C}$ and the switches $\mathrm{Sw}_{1}$ and $\mathrm{Sw}_{2}$ and also there is a minor part i.e inductor $\mathrm{L}$, it is required to limit the inrush current flowing through the thyristors and to avoid resonance with the power system network (usually $6 \%$ wrt Xc). If the capacitor voltage and the network voltage consist of the equal value then the capacitor may be switched with a smallest amount of transients when the thyristor is turned on at that instant. Stepwise control, no harmonics generation since transient component of current can be attenuated in effect and average delay of one half a cycle (maximum one cycle), [11], [12] are the properties of static Thyristor Switched Capacitor.

Although an attractive hypothetical simplicity configuration of the switched capacitor, its attractiveness has been mired by a following number of practical drawbacks: the reactive power compensation is not constant, separate thyristor switches are required for each capacitor bank and therefore the structure is not cost-effective, the constant voltage across the turned off thyristor switch is two times the maximum supply voltage, and the thyristor switch must be protected by an external means against fault currents and transients of line voltage.

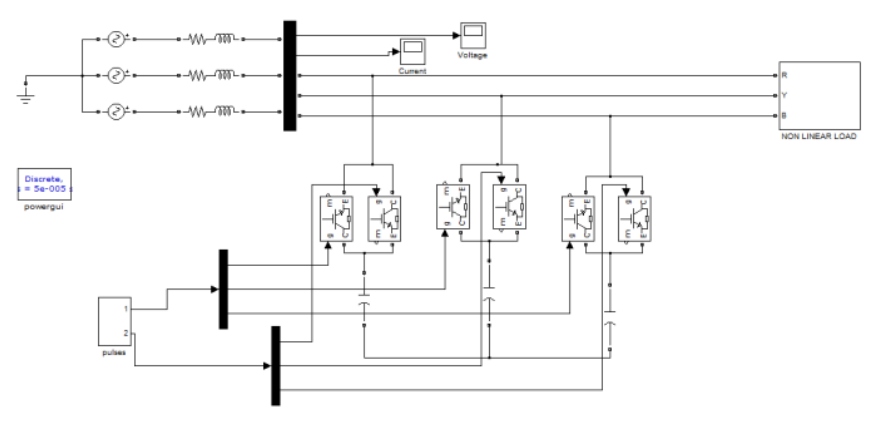

Figure 1: Simulink diagram of thyristor-switched capacitor

\section{Thyristor-Controlled Reactor}

The configuration of a thyristor-controlled Reactor (TCR) which is the group of a static compensator is shown in Figure 2. In most of the cases, the compensator also consists of a fixed capacitor and filter will includes for a low order harmonics, which is not shown in Figure 2. The configuration includes three branches such as an inductor L, and the controlled switches $\mathrm{Sw}_{1}$ and $\mathrm{Sw}_{2}$. Reactors may be controlled using both phase-angle and switched control scheme [13], [14], [15]. When a method of phase-angle control is employed, a constant consumption range of Var is obtained. It results, in the generation of harmonic current which is of odd components during the control method. Full and Partial conduction is achieved for a gating angle of $90^{\circ}$, between $90^{\circ}$ and $180^{\circ}$ respectively, as shown in Figure 3. By increasing the controlled switch gating angle, the fundamental current component flowing through the reactor is reduced. This is corresponding to raise the inductance value and reducing the reactive power which is absorbed by that reactor. However, it should be noted that the change in the current which is flowing through the reactor may only take place at discrete points of time, which means that changes cannot be made further often than once per half-cycle. The TCR type of Static compensators is characterized by the ability to carry out continuous control, practically there are no transients and one half cycle is the maximum delay. The demerits of this arrangement are the generation of low frequency harmonic current components, and higher losses when working in the inductive region (i.e. absorbing reactive power) [13].

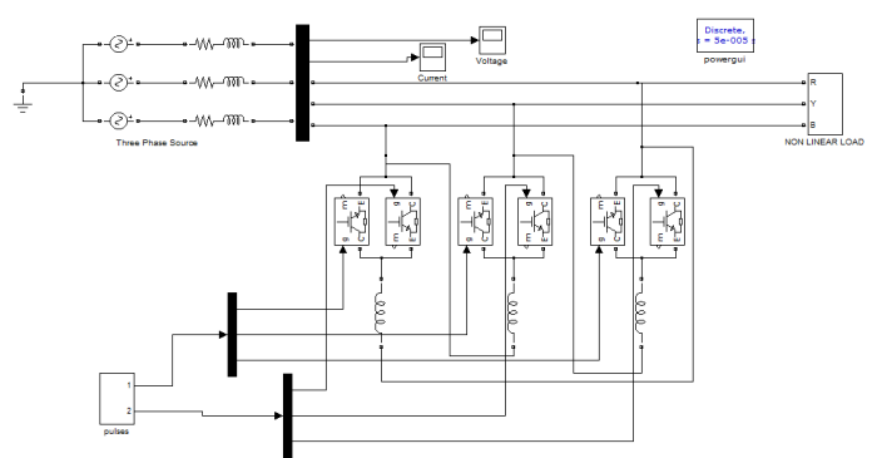

Figure 2: Simulink block diagram of TCR

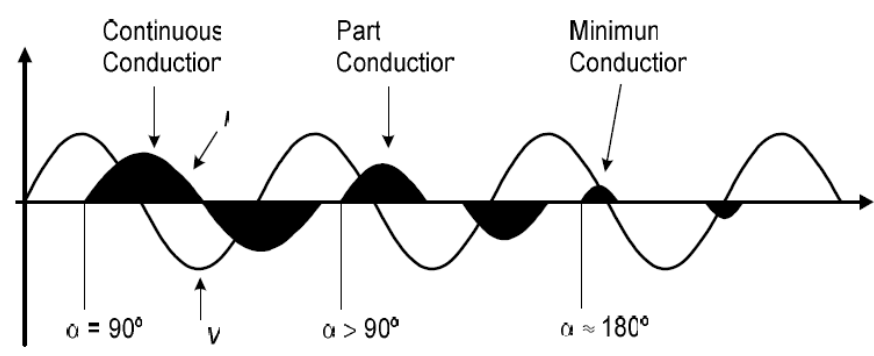

Figure 3: Simulated voltage and current waveforms in a TCR for different thyristor phase-shift angles [20]

In order to eliminate low frequency current harmonics $\left(3^{\text {rd }}, 5^{\text {th }}\right.$, $\left.7^{\text {th }}\right)$, Twelve pulse configurations are also used as shown in Figure 4-b). In this case passive filters are not required, since the $5^{\text {th }}$ and $7^{\text {th }}$ current harmonics are eliminated by the phaseshift introduced by the transformer.
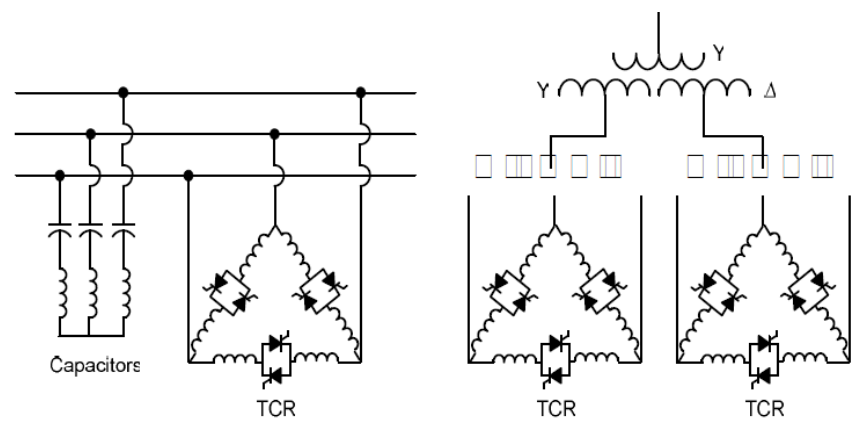

Figure 4: Fixed capacitor-thyristor controlled reactor configuration. (a) Six pulse topology (b) Twelve pulse topology [20] 


\section{United TSC and TCR}

Irrespective of the control range of the reactive power required, any static compensator can be model from one or together of the above point out schemes (i.e. TCR and TSC), as illustrated in Figure 5. In those cases where the power system with thyristor switched capacitors is employed, the Var is separated into an appropriate number of steps and the variation will therefore take place stepwise. Constant control may be achieved with the adding of a thyristor-controlled reactor. If it is requisite to absorb the reactive power, the complete capacitor bank is cut off and the equalizing reactor turns into liable for the absorption. By coordinating the control between the capacitor and the reactor steps, it is feasible to acquire completely step less control.

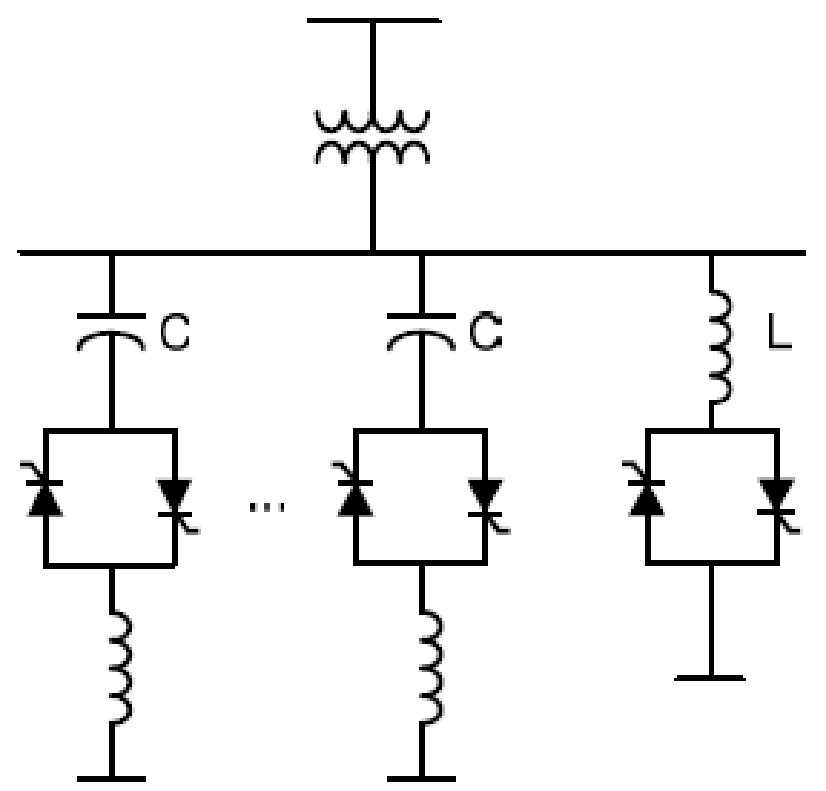

Figure 5: United TSC and TCR configuration [20]

Static compensators of the united TCR and TSC type are typified by a constant control, practically there is no transients, less generation of harmonics (since the controlled reactor rating is small compared to the total reactive power), and flexibility in control and operation. An obvious drawback of the TSC-TCR as contrast with TCR and TSC compensators is offer the higher cost. A smaller TCR rating results in some savings, but these savings are more than absorbed by the cost of the capacitor switches and the more complex control system [11].

To reduce transient phenomena and harmonics distortion, and to improve the dynamics of the compensator, some researchers have applied self commutation to TSC and TCR. Some examples of this can be found in [14], [15]. However, best results have been obtained using self-commutated compensators and these are analyzed in section III.

\section{SELF COMMUTATED VAR COMPENSATORS}

The implementation of self-commutated converters for reactive power compensation has exhibit to be an efficient solution. This type of technology has been employed to implement additional sophisticated compensator apparatus such as unified power flow controllers (UPFCs), static synchronous compensators, and dynamic voltage restorers (DVRs) [16], [17].

With an amazing progress of gate controlled semiconductor devices, concentration has been focused on VAR compensators using self commutated semiconductor devices, capable of injecting or absorbing VAR without requiring huge banks of reactors or capacitors. Number of approaches is achievable including voltage-source and current-source converters. The voltage-source using a capacitor with a controlled de voltage is shown in Figure 6

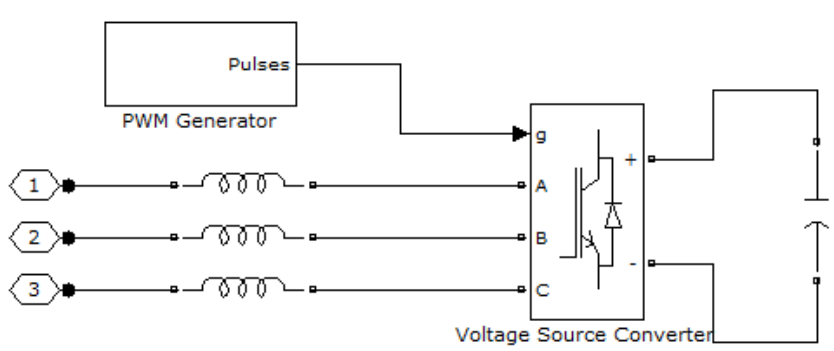

Figure 6: Voltage Source Converter for VAR compensation

The major advantages of self-commutated reactive power compensators are the considerable reduction of size, and the possible reduction in cost attain from the abolition of a huge number of passive apparatus and lower relative capacity requirement for the semiconductor switches [17], [18]. Because of its smaller in size, self-commutated reactive power compensators are robust for applications where space is a premium. Self-commutated converter based compensators are applicable to improve voltage regulation, correct power factor, stabilize transmission systems, and also correct unbalance in the loads [17], [18].

The significant advantages of self-commutated compensators make them an interesting alternative to improve compensation characteristics and also to increase the performance of ac power systems.

\section{SIMULATION RESULT ANALYSIS}

In this Section, the simulation results of proposed configuration as shown in Figure 7 are discussed without and with compensation.

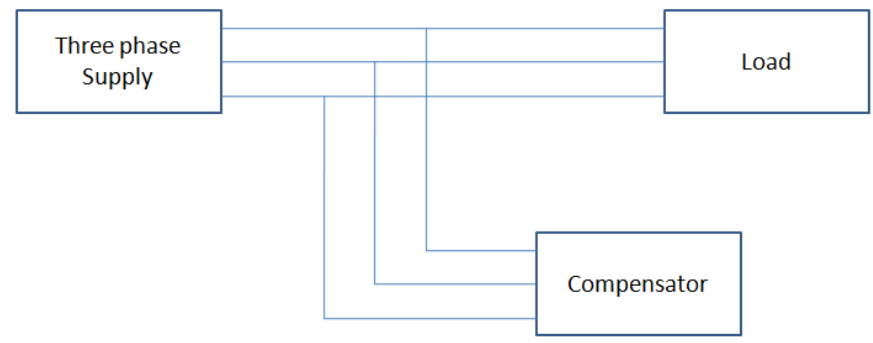

Figure 7: Proposed shunt VAR compensator topology 
The simulation parameters used in this paper is listed in Table I.

Table I: Simulation parameters

\begin{tabular}{|l|l|}
\hline Parameter & Value \\
\hline Source Voltage & $415 \mathrm{~V}$ \\
\hline Source Resistance $\left(\mathrm{R}_{\mathrm{s}}\right)$ & $0.003 \Omega$ \\
\hline Source Inductance & $2.5 \mathrm{mh}$ \\
\hline Non linear load & Diode Bridge Rectifier \\
\hline DC load Resistance & $25 \Omega$ \\
\hline DC load Inductance & $55 \mathrm{mH}$ \\
\hline Supply frequency & $50 \mathrm{~Hz}$ \\
\hline TCR Inductance & $2.5 \mathrm{mH}$ \\
\hline TSC Capacitance & $420 \mu \mathrm{F}$ \\
\hline VSC Parameters & $\mathrm{L}_{\mathrm{f}}=1 \mathrm{mH}, \mathrm{DC}$ Capacitor $\mathrm{C}_{\mathrm{f}}=1 \mu \mathrm{F}$ \\
\hline Switching frequency & $10 \mathrm{kHz}$ \\
\hline
\end{tabular}

\section{Without Compensation}

Figure 8 shows the source voltage of uncompensation system and harmonic spectrum is shown in Figure 9. The total harmonic distortion in this method is $9.36 \%$.

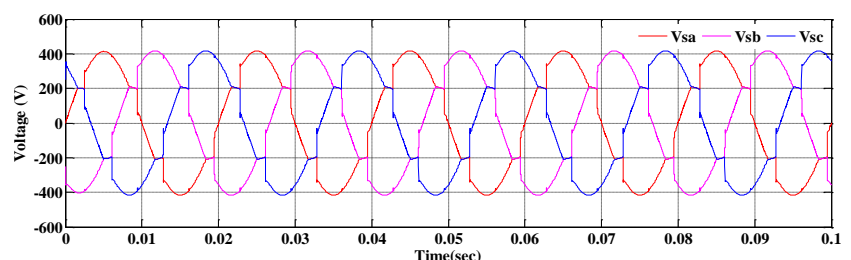

Figure 8: Source Voltage

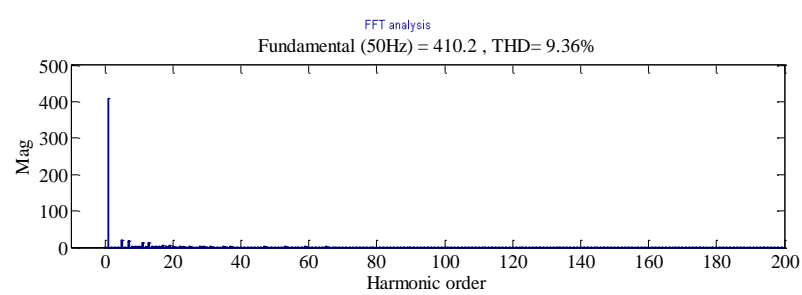

Figure 9: FFT Spectrum of Source Voltage

\section{Conventional Methods}

\section{Synchronous Condenser}

Figure 10 shows the source voltage of the system using Synchronous Condenser and harmonic spectrum is shown in Figure 11. The total harmonic distortion in this method is $8.95 \%$.

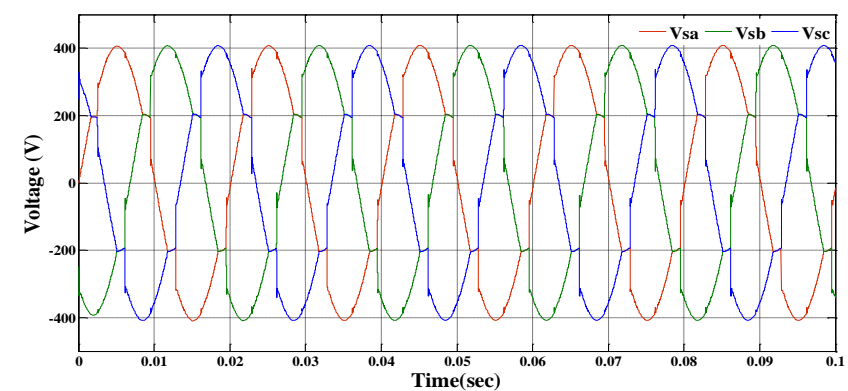

Figure 10: Source Voltage

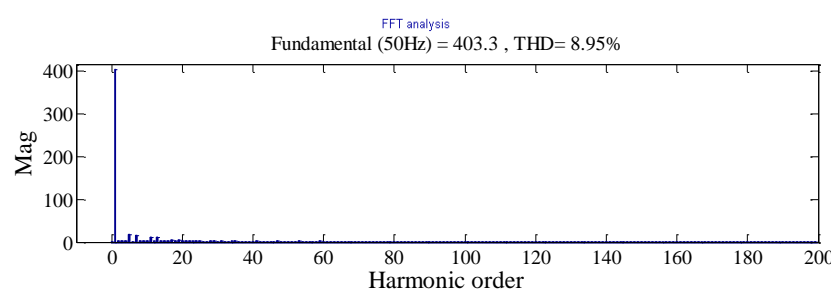

Figure 11: FFT Spectrum of Source Voltage

\section{Thyristor Controlled Reactor}

Figure 12 shows the source voltage of the system using TCR and harmonic spectrum is shown in Figure 13. The total harmonic distortion in this method is $7.73 \%$.

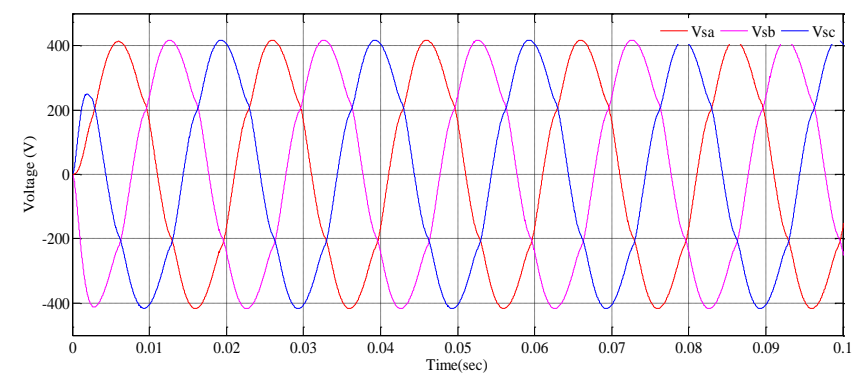

Figure 12: Source Voltage

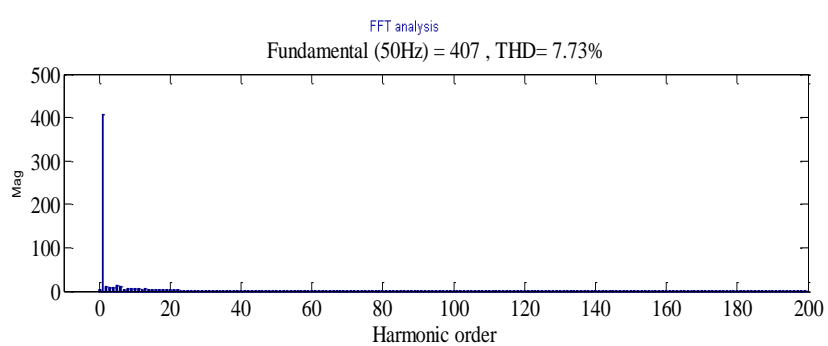

Figure 13: FFT Spectrum of Source Voltage

\section{Thyristor Switched Capacitor}

Figure 14 shows the source voltage of the system using TSC and harmonic spectrum is shown in Figure 15. The total harmonic distortion in this method is $7.65 \%$. 


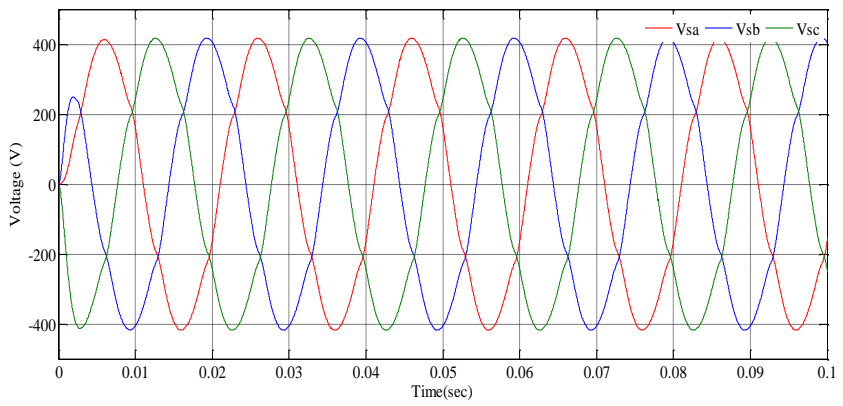

Figure 14: Source Voltage

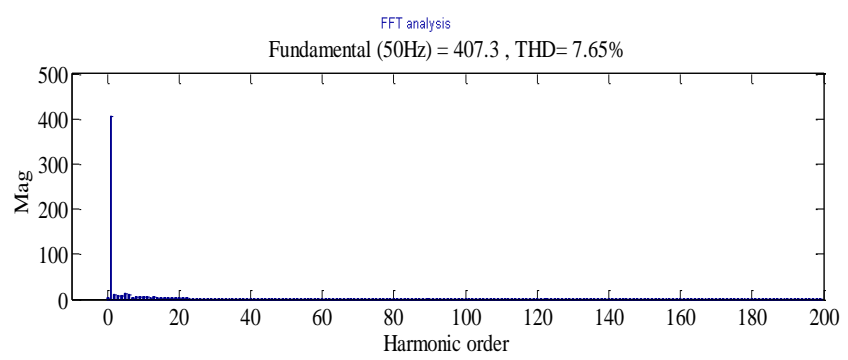

Figure 15: FFT Spectrum of Source Voltage

\section{Voltage Source Converter}

Figure 16 shows the source voltage of the system using VSC and harmonic spectrum is shown in Figure 17. The total harmonic distortion in this method is $4.46 \%$.

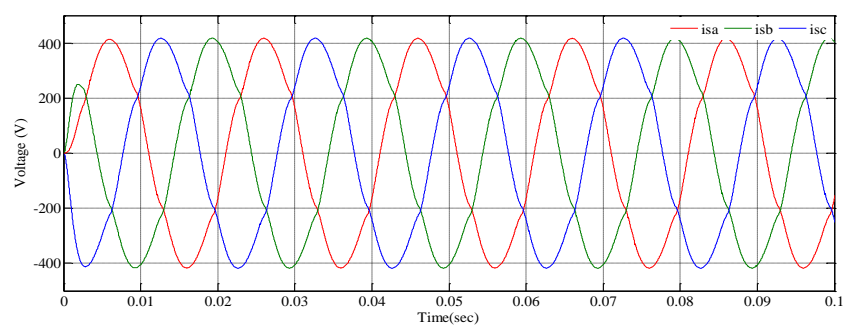

Figure 16: Source Voltage

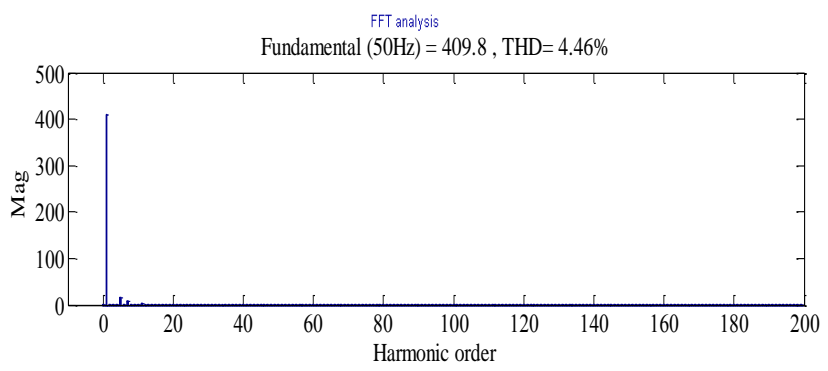

Figure 17: FFT Spectrum of Source Voltage
Table II: \%THD Comparison of VAR methods

\begin{tabular}{|c|c|c|c|c|}
\hline \multirow{2}{*}{$\begin{array}{c}\text { Type of } \\
\text { Compensation }\end{array}$} & \multicolumn{4}{|c|}{$\% \mathrm{THD}$} \\
\hline & $\begin{array}{c}\text { Without } \\
\text { Compensation }\end{array}$ & $\begin{array}{l}\text { Synchronous } \\
\text { condenser }\end{array}$ & TCR TSC & VSC \\
\hline Source Volt & 9.36 & 8.95 & \begin{tabular}{|l|l|}
7.73 & 7.65 \\
\end{tabular} & 4.46 \\
\hline
\end{tabular}

The \% THD Comparison of VAR methods listed in Table II.

\section{CONCLUSION}

In this paper, various conventional techniques for power quality improvement are discussed and tabulated. A summary of THD Comparison of VAR methods are presented. The simulation results for source voltage with harmonic spectrum are presented and observed the \% THD for VSC is $4.46 \%$, which is less when compared with traditional methods.

\section{REFERENCES}

[1]. R. Sastry Vedam, Mulukutla S. Sarma "power Quality VAR Compensation in Power Systems" CRC Press Taylor \& Francis Group, 2009.

[2]. Salem Rahmani, Abdelhamid Hamadi et.al "A Combination of Shunt Hybrid Power Filter and Thyristor-Controlled Reactor for Power Quality" IEEE Transactions on Industrial Electronics, vol. 61, no. 5, May 2014.

[3]. H. Hu, W. Shi, Y. Lu, and Y. Xing, "Design considerations for DSP controlled $400 \mathrm{~Hz}$ shunt active power filter in an aircraft power system," IEEE Trans. Ind. Electron., vol. 59, no. 9, pp. 36243634, Sep. 2012.

[4]. X. Du, L. Zhou, H. Lu, and H.-M. Tai, "DC link active power filter for three-phase diode rectifier," IEEE Trans. Ind. Electron., vol. 59, no. 3, pp. 14301442, Mar. 2012.

[5]. M. Angulo, D. A. Ruiz-Caballero, J. Lago, M. L. Heldwein, and S. A. Mussa, "Active power filter control strategy with implicit closed loop current control and resonant controller," IEEE Trans. Ind. Electron., vol. 60, no. 7, pp. 2721-2730, Jul. 2013.

[6]. X. Wang, F. Zhuo, J. Li, L. Wang, and S. Ni, "Modeling and control of dual-stage high-power multifunctional PV system in d-q-0 coordinate," IEEE Trans. Ind. Electron., vol. 60, no. 4, pp. 15561570, Apr. 2013.

[7]. J. A. Munoz, J. R. Espinoza, C. R. Baier, L. A. Moran, E. E. Espinosa, P. E. Melin, and D. G. Sbarbaro, "Design of a discrete-time linear control strategy for a multi cell UPQC," IEEE Trans. Ind. Electron., vol. 59, no. 10, pp. 3797-3807, Oct. 2012.

[8]. L. Junyi, P. Zanchetta, M. Degano, and E. Lavopa, "Control design and implementation for high performance shunt active filters in aircraft power grids," IEEE Trans. Ind. Electron., vol. 59, no. 9, pp. 3604-3613, Sep. 2012. 
[9]. C. W. Taylor, "Improving grid behavior," IEEE Spectr., vol. 36, no. 6, pp. 40-45, Jun. 1999.

[10]. Canadian Electrical Association, "Static compensators for reactive power control," 1984.

[11]. H. Frank and S. Ivner, "Thyristor-controlled shunt compensation in power networks," ASEA J., vol. 54, pp. 121-127, 1981.

[12]. H. Frank and B. Landstrom, "Power factor correction with Thyristor-controlled capacitors," ASEA J., vol. 45, no. 6, pp.180-184, 1971

[13]. S. Torseng, "Shunt-connected reactors and capacitors controlled by thyristors," IEE Proc. Part C, vol. 128, no. 6, pp. 366-373, Nov. 1981.

[14]. A. K. Chakravorti and A. E. Emanuel, "A current regulated switched capacitor static volt ampere reactive compensator," IEEE Trans. Ind. Appl., vol. 30, no. 4, pp. 986-997, Jul./Aug. 1994.

[15]. H. Jin, G. Goós, and L. Lopes, "An efficient switched-reactor based static var compensator," IEEE Trans. Ind. Appl., vol. 30, no. 4, pp. 997-1005, Jul./Aug. 1994.

[16]. N. Hingorani and L. Gyugyi, Understanding FACTS, Concepts and Technology of Flexible ac Transmission Systems. New York: IEEE Press, 2000.

[17]. L. Morán, P. Ziogas, and G. Joos, "Analysis and design of a synchronous solid-stateVar compensator," IEEE Trans. Ind. Appl., vol. IA-25, no. 4, pp. 598-608, Jul./Aug. 1989.

[18]. J. W. Dixon, J. García, and L. Morán, "Control system for a three phase active power filter which simultaneously compensates power factor and unbalanced loads," IEEE Trans. Ind. Electron., vol. 42, no. 6, pp. 636-641, Dec. 95.

[19]. R. Grünbaum, M. Noroozian, and B. Thorvaldsson, "FACTS-powerful systems for flexible power transmission,” ABB Rev., pp. 4-17, May 1999.

[20]. Juan Dixon, and José Rodríguez "Reactive power compensation technologies: State-of-the-Art Review" proceedings of the IEEE, Vol. 93, NO. 12, December 2005.

\section{Authors}

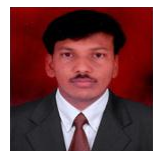

V. Narasimhulu received the B. Tech (Electrical and Electronic Engineering) degree from the JNT University, Hyderabad in 2005, M. Tech (Power and Industrial Drives) from the JNT University, Anantapur in 2009. Currently he is the Research Scholar in EEE Department at JNTUK, Kakinada, Andhra Pradesh. He has published 5 research papers in international conferences and journals. His area of interest includes Power Electronics, Power Systems, Electrical Machines, Drives, Power Quality and FACTS controllers. E-mail: narasimhapid@gmail.com

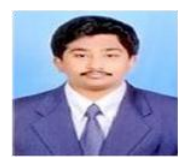

Dr. D. V. Ashok Kumar, is graduated in 1996, Masters in 2000 from J.N.T.U.C.E, Anantapur and Ph.D in 2008 from the same university. He worked 12 years at R.G.M. College of Engineering Technology, Nandyal, A.P. in the cadars of Assistant Professor, Assoc.Professor, Professor and Head of Electrical and Electronics Engg. Department. Worked as Principal at Syamaladevi institute of Technology for women, Nandyal from 2008 to June 2015. Working as Prof. of EEE and Dean Administration since July 2015 to till date. He has published 30 research papers in national and international conferences and journals. He has attended 10 National \& International workshops. His areas of interests are Electrical Machines, Power Systems \& Solar Energy. He is a member of IEEE, I.S.T.E, K.D.T.F \& SESI.

E-mail: principal.sdit@gmail.com

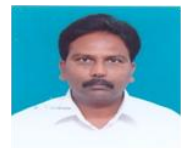

Dr. Ch. Sai Babu received the B.E from Andhra University (Electrical \& Electronics Engineering), M. Tech in Electrical Machines and Industrial Drives from REC, Warangal and Ph. D in Reliability Studies of HVDC Converters from JNTU, Hyderabad. Currently he is the Professor of E.E.E and officer on special duty at JNT University, Kakinada. He has published several National and International Journals and Conferences. His area of interest is Power Electronics and Drives, Power System Reliability, HVDC Converter Reliability, Optimization of Electrical Systems and Real Time Energy Management. E-mail: chs_eee@yahoo.co.in 